\title{
Allelotype of 28 human breast cancer cell lines and xenografts
}

\author{
IC Harkes', F Elstrodt', WNM Dinjens², M Molier', JGM Klijn', EMJJ Berns' and M Schutte*,I \\ 'Department of Medical Oncology, Josephine Nefkens Institute, Erasmus University Medical Center, PO Box 1738, 3000 DR Rotterdam, The Netherlands; \\ ${ }^{2}$ Department of Pathology, Josephine Nefkens Institute, Erasmus University Medical Center, PO Box 1738, 3000 DR Rotterdam, The Netherlands
}

Heterozygous loss of relatively large chromosomal regions is a hallmark of the inactivation of tumour suppressor genes. Searching for deletions in cancer genomes therefore provides an attractive option to identify new tumour suppressor genes. Here, we have performed a genome-wide survey for regions exhibiting allelic loss in 24 commercially available breast cancer cell lines and four breast cancer xenografts, using microsatellite analysis. The assembled allelotype revealed an average fractional allelic loss of 0.34 . A total of I 9 arms had low allelic loss frequencies $(<25 \%)$ and 17 arms had moderate allelic loss frequencies $(25-50 \%)$. Five chromosomal arms were deleted in more than half of the breast cancer samples (8p, I0q, I3q, I7p, and 17q). Three of these frequently lost chromosomal arms had not been identified as such by comparative genome hybridisation, illustrating the higher sensitivity of microsatellite analysis for the detection of allelic losses. As we present allelic loss data of individual samples, our allelotype should not only aid the identification of new breast cancer genes but also provides a baseline for myriad studies involving these breast cancer cell lines. British Journal of Cancer (2003) 89, 2289 -2292. doi:I0.1038/sj.bjc.660I448 www.bjcancer.com (c) 2003 Cancer Research UK

Keywords: allelic loss; breast cancer; cell lines; loss of heterozygosity; xenografts

Genetic analyses of sporadic breast cancers have thus far identified few archetypal tumour suppressor genes involved in the development of these tumours. The p53 tumour suppressor gene was found to be mutated in $20-40 \%$ of breast cancers, and the $R B 1$ and E-cadherin genes were inactivated in 10-20\% of tumours (Lee et al, 1988; T’Ang et al, 1988; Hollstein et al, 1991; Berns et al, 1995, 2000; Berx et al, 1995, 1996; van de Wetering et al, 2001). Other tumour suppressor genes were mutated in only a minority of sporadic breast cancers $(<10 \%)$; that is, $A P C, A T M, B R C A 1$, BRCA2, MAP2K4, PTEN, p16, SMAD4, VHL, and the mismatch repair genes $M L H 1, M S H 2$, and $M S H 6$.

The biallelic inactivation of tumour suppressor genes generally involves a small intragenic alteration in one copy of the gene, combined with the loss of a larger chromosomal region containing the other allele. Although the smaller mutations may present problems in detection, the larger regions of deletion are readily identifiable by genomic screening. An allelotype is a genome-wide survey for regions that are characteristically deleted in a tumour type (Vogelstein et al, 1989). Such identified regions of frequent allelic loss are thought to be indicative of the location of tumour suppressor genes. Here, we present an allelotype of 24 commercially available breast cancer cell lines and four breast cancer xenografts.

\section{MATERIALS AND METHODS}

\section{Samples}

The 28 human breast cancer samples used in this study are listed in Figure 1. All 24 breast cancer cell lines were obtained from

*Correspondence: Dr M Schutte; E-mail: a.schutte@erasmusmc.nl Received 25 March 2003; revised 27 August 2003; accepted 2 October 2003
American Type Culture Condition and were grown according to their recommendations. The four breast cancer xenografts were generated by implantation of breast cancer specimens into immune-deficient mice, as described (Sakakibara et al, 1996). Family history of breast cancer or BRCA1 and BRCA2 mutational status are not known for any of the breast cancer samples. Controls $(n=25)$ were non-neoplastic blood or tissue samples from randomly selected, apparently healthy Dutch individuals. Genomic DNA was extracted using the Qiagen DNeasy kit. Microsatellite analyses indicated that all samples were unique and monoclonal. Of the 28 breast cancer samples, $22(79 \%)$ were shown to be heterozygous for X-chromosome microsatellites (Figure 1). Ychromosome microsatellite DYS200 was detected in all malederived controls, but not in any of the breast cancer samples nor in the female-derived controls.

\section{Microsatellite analysis}

Microsatellites were PCR-amplified as previously described (van de Wetering et al, 2001). PCR products were separated by electrophoresis in standard denaturing sequencing gels and the reactions were visualised by autoradiography. All reactions were scored by at least two investigators who were unaware of each other's scores. When the scores were discordant, data were reevaluated and reactions were repeated when desired. Primer sequences are available upon request.

\section{RESULTS AND DISCUSSION}

We analysed 24 commercially available breast cancer cell lines and four breast cancer xenografts for allelic losses at all 41 nonacrocentric chromosomal arms, by PCR amplification of microsatellites. A single locus was analysed for each chromosomal arm, 


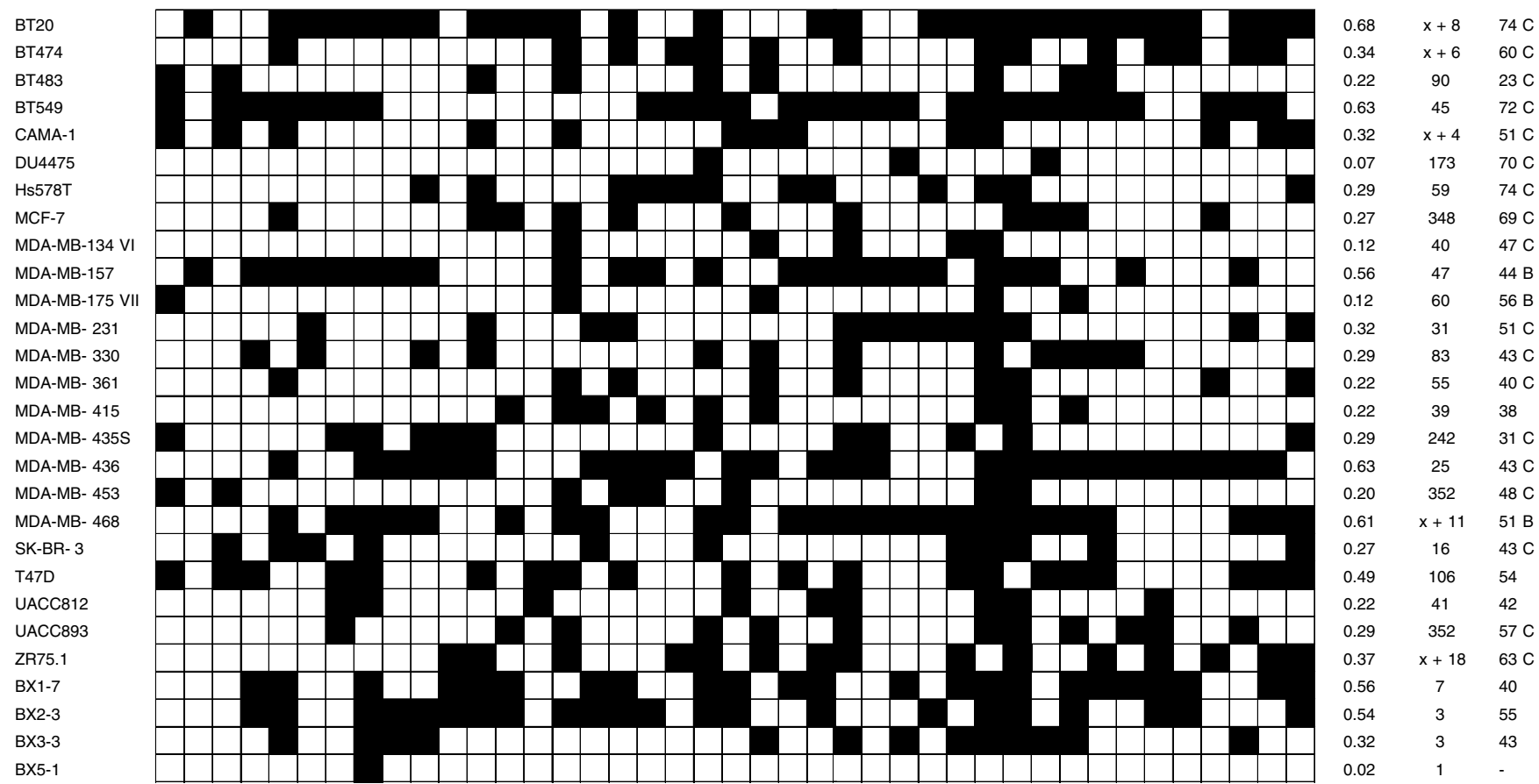

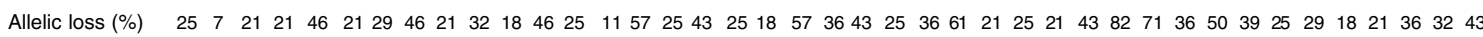

Figure I Presumptive allelic losses of human breast cancer samples. In all 24 ATCC breast cancer cell lines and four xenografts (with BX-identifiers) are listed on the left and 4I non-acrocentric chromosomal arms are listed on the top. White squares: both alleles had been retained; black squares: allelic loss was presumed; FAL: fractional allelic loss; passage no.: number of passages that the tumour cells had been propagated in vitro or in vivo, where $x$ indicates an unknown number of passages that the cells had undergone prior to culture in our laboratory; age: age of the patients at breast cancer diagnosis or resection of the tumour cells, followed by their ethnicity where " $\mathrm{C}$ " and "B" indicate Caucasian and Black, respectively.

encompassing a known tumour suppressor gene at $5 \mathrm{q} 21(A P C)$, 9p21 (p16), 10q23 (PTEN), 13q12 (BRCA2), 16p13 (AXIN1), 16q22 (E-cadherin), 17p13 (p53), 17q21 (BRCA1), 18q21 (SMAD4), 19p13 (STK11), and 22q11 (hSNF5). Since constitutional non-neoplastic tissues were not available for any of the breast cancer samples, allelic losses were presumed based on statistical arguments. Multiple microsatellite markers were therefore designed within a 5 -centiMorgan locus, thus reducing the odds of a deletion breakpoint between markers within a locus. Analysis of genomic DNA from 25 randomly selected non-neoplastic control samples revealed heterozygosity ratios for all microsatellite markers. Heterozygosity ratios generally were about 0.1 lower than those reported in the NCBI database, but higher ratios were also observed. The number of microsatellites that was analysed for each locus was such that the probability for a heterozygous sample to have a single allele size for each of the microsatellites within the locus was less than $5 \%$, based on the heterozygosity ratios of the used markers. Allelic loss of a chromosomal locus was presumed when a breast cancer sample had a homozygous allele pattern for all microsatellites within the locus (with $P<0.05$ for each locus). In total, 146 microsatellites were analysed, resulting in an average of 3.6 markers per locus and an average $P$-value of 0.01 . A homozygous allele pattern was observed for the heterozygous control samples at eight of $986(1 \%)$ analysed loci, thus validating the statistical approach and implying an overall error rate for the complete allelotype of about $1 \%$.

The presumptive allelic losses of all 28 breast cancer samples are detailed in Figure 1. The fractional allelic loss (FAL; i.e., the fraction of chromosomal arms that are lost in a particular sample (Vogelstein et al, 1989)) ranged from 0.02 for xenograft BX5-1 to 0.68 for cell line BT20 (one and 28 of a total of 41 arms, respectively). The average FAL among all 28 breast cancer samples was 0.34 , with an apparently normal distribution pattern of FAL values. This distribution pattern is in contrast to that seen for colorectal cancer, for example, where tumours with the microsatellite instability (MIN) phenotype had distinctly lower FAL values than tumours with the chromosome instability (CIN) phenotype (Lengauer et al, 1998). Analysis of the 28 breast cancer samples from our cohort with markers diagnostic for the MIN phenotype (BAT25, BAT26, and BAT40) revealed two breast cancer samples each with an instable length of only the BAT40 marker (i.e., MDA-MB-157 and MDA-MB-175VII), whereas the remaining samples all had stable lengths of all three BAT markers. The exclusive CIN phenotype among the 28 breast cancer samples from our cohort is likely reflected in the relatively high average FAL of 0.34 among these samples (Lengauer et al, 1998; Orr-Weaver and Weinberg, 1998; Loeb, 2001).

A compilation of the presumptive allelic losses of the 28 breast cancer samples is shown in Figure 2. Low allelic loss frequencies ( $\leqslant 25 \%$ of the samples) were seen at 19 chromosomal arms and 17 chromosomal arms had moderately frequent allelic losses (25-50\% of the samples). Five chromosomal arms were lost in more than half of the samples $(8 p, 10 q, 13 q, 17 p$, and $17 \mathrm{q})$. It should be noted that our allelic loss frequencies are conservative estimates of the true extent of allelic losses, as all subchromosomal deletions not involving the analysed locus would go undetected.

Several breast cancer allelotypes have been reported (Kerangueven et al, 1997; Mertens et al, 1997; Davidson et al, 2000; Forozan et al, 2000; Kytola et al, 2000; Osborne and Hamshere, 2000). In general, frequencies of allelic loss reported in the literature are lower than the frequencies identified in our cohort of breast cancer samples. Discrepancies in allelic loss frequencies may have three, not mutually exclusive, reasons. First, allelic losses could result from genetic instability due to selective pressures during ex vivo propagation of the breast cancer cells, either in cell culture or as 
xenograft. Deletions of genetic material could occur at any time during propagation of the tumour cells or be most pronounced early in establishing the cell lines or xenografts. In our cohort of breast cancer cell lines, FAL values did not correlate with the number of culture passages (Figure 1), arguing against artefactual allelic deletions during in vitro propagation. The five cell lines with extreme high passage numbers had, in fact, FAL values below the average FAL of 0.34 (i.e., DU4475, MCF-7, MDA-MB-435S, MDAMB-453, and UACC893; Figure 1). As original (preculture or prexenograft) tumour specimens were not available for any of the 28 breast cancer samples from our cohort, we can not, however, conclusively exclude artefactual allelic deletions. A single report has appropriately addressed the issue of artefactual in vitro deletions (Wistuba et al, 1998). Cell lines of 17 breast cancer specimens had been established and the cells had been propagated in vitro for a median period of 2 years. Comparison of 867 microsatellite analyses of the 17 cell lines to those of their corresponding archival tumour specimens revealed an overall concordance of $96 \%$, indicating that allelic deletion at any time during in vitro propagation of the breast cancer cells is negligible. As for xenografts, studies on pancreatic cancer have shown that allelic deletions do not occur during in vivo propagation of tumour cells in immune-deficient mice (Caldas et al, 1994; Hahn et al, 1995). Whereas the occurrence of artefactual allelic deletions during ex vivo propagation of cancer cells has often been suggested, evidence for such genetic instability has, to the best of our knowledge, never been provided. A second, more likely reason for the higher frequencies of allelic loss in our allelotype is a more accurate microsatellite analysis of these breast cancer samples, as they all consist solely of neoplastic human cells. An extensive host desmoplastic response to the tumour cells is indeed characteristic of most breast cancers, resulting in an admixture of non-neoplastic cells in the tumour specimens that will severely hamper genetic analyses. Imbalances in allele quantities in microsatellite analyses (illustrated in Figure 3) always reflect genomic amplifications when pure tumour samples are used, such as our breast cancer cell lines or xenografts. We observed allelic imbalances for multiple microsatellite markers only at chromosomal arm $8 \mathrm{q}$ for six of the

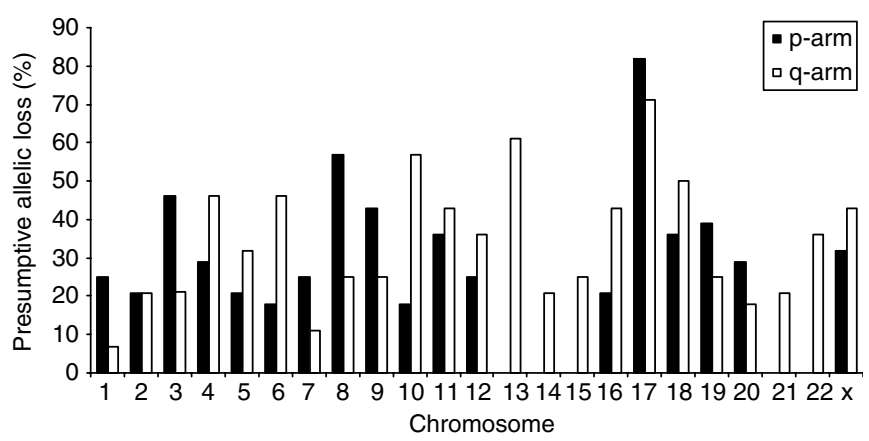

Figure 2 Allelotype of 28 human breast cancer cell lines and xenografts.
28 breast cancer samples and at $20 \mathrm{q}$ for two samples, whereas imbalances at other loci were only occasionally observed. When primary breast cancer specimens are used, however, allelic imbalances may also be due to residual non-neoplastic cells in the samples, resulting in a major amplification product of the retained allele and a minor amplification product of the lost allele. The non-neoplastic cell content in tumour specimens may even be as such that allelic losses go undetected. Allelic loss frequencies in primary breast cancer specimens will therefore generally be lower than those obtained for cell lines, xenografts, or micro-dissected tumours. As for the five chromosomal arms that we found to be most frequently deleted, comparable frequencies of allelic loss $(>50 \%)$ in breast cancer specimens have been reported for $8 \mathrm{p}$, $17 \mathrm{p}$, and $17 \mathrm{q}$, indicating that our allelotype indeed reflects genomic deletions as they occur during breast tumorigenesis (Devilee et al, 1989, 1991a, 1991b; Sato et al, 1990, 1991; Cornelis et al, 1994; Aldaz et al, 1995; Bieche and Lidereau, 1995; Fujii et al, 1996; Kerangueven et al, 1997; Anbazhagan et al, 1998; Fukino et al, 1999; Forozan et al, 2000; Shen et al, 2000). Third, allelic losses may be masked in karyotype-based techniques, due to genomic amplifications or chromosomes that are aberrantly duplicated through nondisjunction at cellular division. Indeed, two or more copies of a chromosome have been observed in tumour karyotypes, even though molecular analysis with polymorphic markers had shown that those tumours had loss of heterozygosity for that particular chromosome (Lengauer et al, 1998). As the comparative genome hybridisation (CGH) technique does not distinguish between paternal and maternal chromosomes, this method is more likely to underestimate allelic loss frequencies than microsatellite analysis. Comparison of our allelotype with three studies that also included the ATCC breast cancer cell lines revealed that the CGH studies had not detected one-quarter to half of the chromosomal arms with allelic loss that we identified using microsatellite analysis (Davidson et al, 2000; Forozan et al, 2000; Kytola et al, 2000). Comparison of the studies is, however, somewhat problematic. Our allelotype, for example, had not detected about one-quarter of the losses identified by $\mathrm{CGH}$, presumably related to the limited resolution of our allelotype (one locus per chromosomal arm). There were also differences among the three CGH studies. Most striking was the consistent underestimation of the allelic losses at $17 \mathrm{p}$ and $17 \mathrm{q}$ by CGH, likely due to several regions of amplification that are known to be present at this chromosome, such as the ERBB2 gene at $17 \mathrm{q} 12$. Losses at $10 \mathrm{q}$ and $13 q$ were variably underestimated, while loss at $8 p$ was among the most frequent losses in all studies.

The wide range from $7 \%$ allelic loss at $1 \mathrm{q}$ to $82 \%$ at $17 \mathrm{p}$ that we observed in our breast cancer allelotype indicated a nonrandom deletion of genetic material, suggestive of the location of tumour suppressor genes at the sites of frequent allelic loss. Chromosomal arm $17 \mathrm{p}$ contains the $p 53$ and MAP2K4 tumour suppressor genes that were mutated in $20(71 \%)$ and three $(11 \%)$ of the 28 breast cancer samples, respectively, with one tumour being double mutant (Wasielewski and Schutte, manuscript in preparation, and (Su et al, 2002). Together these mutation account for $88 \%$ of the $17 \mathrm{p}$ deletions positional candidate genes for the frequent

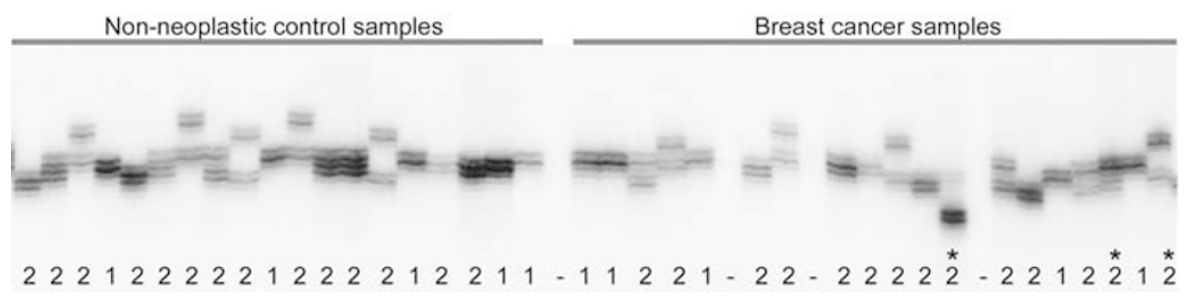

Figure 3 Microsatellite analysis of marker D8S88 in breast cancer samples and non-neoplastic control samples. I: one allele size detected; 2: two allele sizes detected; asterix: possible allelic imbalance due to genomic amplification of the locus. 
allelic losses at $10 \mathrm{q}, 13 \mathrm{q}$, and $17 \mathrm{q}$ are PTEN, BRCA2 and $R B 1$, and $B R C A 1$. Systematic mutational analyses of these tumour suppressor genes in this cohort of commercially available breast cancer samples should reveal whether these known genes indeed were the targets of the frequent allelic losses, or that other new tumour suppressor genes are likely to be located at these chromosomal sites.

\section{REFERENCES}

Aldaz CM, Chen T, Sahin A, Cunningham J, Bondy M (1995) Comparative allelotype of in situ and invasive human breast cancer: high frequency of microsatellite instability in lobular breast carcinomas. Cancer Res 55: 3976-3981

Anbazhagan R, Fujii H, Gabrielson E (1998) Allelic loss of chromosomal arm $8 \mathrm{p}$ in breast cancer progression. Am J Pathol 152: 815-819

Berns EM, de Klein A, van Putten WL, van Staveren IL, Bootsma A, Klijn JG, Foekens JA (1995) Association between RB-1 gene alterations and factors of favourable prognosis in human breast cancer, without effect on survival. Int J Cancer 64: 140-145

Berns EM, Foekens JA, Vossen R, Look MP, Devilee P, Henzen-Logmans SC, van Staveren IL, van Putten WL, Inganas M, Meijer-van Gelder ME, Cornelisse C, Claassen CJ, Portengen H, Bakker B, Klijn JG (2000) Complete sequencing of TP53 predicts poor response to systemic therapy of advanced breast cancer. Cancer Res 60: 2155-2162

Berx G, Cleton-Jansen AM, Nollet F, de Leeuw WJ, van de Vijver M, Cornelisse C, van Roy F (1995) E-cadherin is a tumour/invasion suppressor gene mutated in human lobular breast cancers. EMBO J 14: $6107-6115$

Berx G, Cleton-Jansen AM, Strumane K, de Leeuw WJ, Nollet F, van Roy F, Cornelisse C (1996) E-cadherin is inactivated in a majority of invasive human lobular breast cancers by truncation mutations throughout its extracellular domain. Oncogene 13: 1919-1925

Bieche I, Lidereau R (1995) Genetic alterations in breast cancer. Genes Chromosomes Cancer 14: 227-251

Caldas C, Hahn SA, da Costa LT, Redston MS, Schutte M, Seymour AB, Weinstein CL, Hruban RH, Yeo CJ, Kern SE (1994) Frequent somatic mutations and homozygous deletions of the p16 (MTS1) gene in pancreatic adenocarcinoma. Nat Genet 8: 27-32

Cornelis RS, van Vliet M, Vos CB, Cleton-Jansen AM, van de Vijver MJ, Peterse JL, Khan PM, Borresen AL, Cornelisse CJ, Devilee P (1994) Evidence for a gene on 17p13.3, distal to TP53, as a target for allele loss in breast tumors without p53 mutations. Cancer Res 54: 4200-4206

Davidson JM, Gorringe KL, Chin SF, Orsetti B, Besret C, Courtay-Cahen C, Roberts I, Theillet C, Caldas C, Edwards PA (2000) Molecular cytogenetic analysis of breast cancer cell lines. $\mathrm{Br} J$ Cancer 83: $1309-1317$

Devilee P, van den Broek M, Kuipers-Dijkshoorn N, Kolluri R, Khan PM, Pearson PL, Cornelisse CJ (1989) At least four different chromosomal regions are involved in loss of heterozygosity in human breast carcinoma. Genomics 5: $554-560$

Devilee P, van den Broek M, Mannens M, Slater R, Cornelisse CJ, Westerveld A, Khan PM (1991a) Differences in patterns of allelic loss between two common types of adult cancer, breast and colon carcinoma, and Wilms' tumor of childhood. Int J Cancer 47: 817-821

Devilee P, van Vliet M, van Sloun P, Kuipers Dijkshoorn N, Hermans J, Pearson PL, Cornelisse CJ (1991b) Allelotype of human breast carcinoma: a second major site for loss of heterozygosity is on chromosome 6q. Oncogene 6: 1705-1711

Forozan F, Mahlamaki EH, Monni O, Chen Y, Veldman R, Jiang Y, Gooden GC, Ethier SP, Kallioniemi A, Kallioniemi OP (2000) Comparative genomic hybridization analysis of 38 breast cancer cell lines: a basis for interpreting complementary DNA microarray data. Cancer Res 60: $4519-4525$

Fujii H, Szumel R, Marsh C, Zhou W, Gabrielson E (1996) Genetic progression, histological grade, and allelic loss in ductal carcinoma in situ of the breast. Cancer Res 56: 5260-5265

Fukino K, Iido A, Teramoto A, Sakamoto G, Kasumi F, Nakamura Y, Emi M (1999) Frequent allelic loss at the TOC locus on 17q25.1 in primary breast cancers. Genes Chromosomes Cancer 24: 345-350

\section{ACKNOWLEDGEMENTS}

We thank Dr Elizabeth Repasky for generously providing the breast cancer xenografts, Ad Gilles for providing DNA from control samples, and Hein Sleddens for performing MSI analyses. This work was supported by The Dutch Cancer Society, De Kock Society, and Nijbakker-Morra Society.

Hahn SA, Seymour AB, Hoque AT, Schutte M, da Costa LT, Redston MS Caldas C, Weinstein CL, Fischer A, Yeo CJ, Hruban RH, Kern SE (1995) Allelotype of pancreatic adenocarcinoma using xenograft enrichment. Cancer Res 55: $4670-4675$

Hollstein M, Sidransky D, Vogelstein B, Harris CC (1991) p53 mutations in human cancers. Science 253: 49-53

Kerangueven F, Noguchi T, Coulier F, Allione F, Wargniez V, SimonyLafontaine J, Longy M, Jacquemier J, Sobol H, Eisinger F, Birnbaum D (1997) Genome-wide search for loss of heterozygosity shows extensive genetic diversity of human breast carcinomas. Cancer Res 57: 5469-5474

Kytola S, Rummukainen J, Nordgren A, Karhu R, Farnebo F, Isola J, Larsson C (2000) Chromosomal alterations in 15 breast cancer cell lines by comparative genomic hybridization and spectral karyotyping. Genes Chromosomes Cancer 28: $308-317$

Lee EY, To H, Shew JY, Bookstein R, Scully P, Lee WH (1988) Inactivation of the retinoblastoma susceptibility gene in human breast cancers. Science 241: $218-221$

Lengauer C, Kinzler KW, Vogelstein B (1998) Genetic instabilities in human cancers. Nature 396: 643 -649

Loeb LA (2001) A mutator phenotype in cancer. Cancer Res 61: 3230-3239

Mertens F, Johansson B, Hoglund M, Mitelman F (1997) Chromosomal imbalance maps of malignant solid tumors: a cytogenetic survey of 3185 neoplasms. Cancer Res 57: 2765-2780

Orr-Weaver TL, Weinberg RA (1998) A checkpoint on the road to cancer. Nature 392: $223-224$

Osborne RJ, Hamshere MG (2000) A genome-wide map showing common regions of loss of heterozygosity/allelic imbalance in breast cancer. Cancer Res 60: 3706-3712

Sakakibara T, Xu Y, Bumpers HL, Chen FA, Bankert RB, Arredondo MA, Edge SB, Repasky EA (1996) Growth and metastasis of surgical specimens of human breast carcinomas in SCID Mice. Cancer J Sci Am 2: $291-300$

Sato T, Akiyama F, Sakamoto G, Kasumi F, Nakamura Y (1991) Accumulation of genetic alterations and progression of primary breast cancer. Cancer Res 51: 5794-5799

Sato T, Tanigami A, Yamakawa K, Akiyama F, Kasumi F, Sakamoto G, Nakamura Y (1990) Allelotype of breast cancer: cumulative allele losses promote tumor progression in primary breast cancer. Cancer Res 50: $7184-7189$

Shen CY, Yu JC, Lo YL, Kuo CH, Yue CT, Jou YS, Huang CS, Lung JC, Wu CW (2000) Genome-wide search for loss of heterozygosity using laser capture microdissected tissue of breast carcinoma: an implication for mutator phenotype and breast cancer pathogenesis. Cancer Res 60: 3884-3892

Su GH, Song JJ, Repasky EA, Schutte M, Kern SE (2002) Mutation rate of MAP2K4/MKK4 in breast carcinoma. Hum Mutat 19: $81-84$

T'Ang A, Varley JM, Chakraborty S, Murphree AL, Fung YK (1988) Structural rearrangement of the retinoblastoma gene in human breast carcinoma. Science 242: $263-266$

van de Wetering $M$, Barker N, Harkes IC, van der Heyden M, Dijk NJ, Hollestelle A, Klijn JG, Clevers H, Schutte M (2001) Mutant E-cadherin breast cancer cells do not display constitutive Wnt signaling. Cancer Res 61: $278-284$

Vogelstein B, Fearon ER, Kern SE, Hamilton SR, Preisinger AC, Nakamura Y, White R (1989) Allelotype of colorectal carcinomas. Science 244: 207 211

Wistuba II, Behrens C, Milchgrub S, Syed S, Ahmadian M, Virmani AK, Kurvari V, Cunningham TH, Ashfaq R, Minna JD, Gazdar AF (1998) Comparison of features of human breast cancer cell lines and their corresponding tumors. Clin Cancer Res 4: 2931-2938 